\title{
Pharmacological Therapy for COVID-19: Where Are We Now and Where Are We Going?
}

\author{
Baha Eldin Hassan Juma", Alya Salah Babiker Higazy², and Mohamed H \\ Ahmed $^{3}$ \\ ${ }^{1}$ Department of pediatrics-PICU section, Hamad Medical Corporation, Weill Cornell medical \\ college- Doha, Qatar \\ ${ }^{2}$ Department of pharmacy-clinical pharmacy section, Hamad Medical Corporation, Doha, Qatar \\ ${ }^{3}$ Department of Medicine and HIV metabolic clinic, Milton Keynes University Hospital NHS \\ Foundation Trust, Eagelstone, Milton Keynes, Buckinghamshire, UK
}

Corresponding Author:

Mohamed H Ahmed;

email: Mohamed.Hassan-

Ahmed@mkuh.nhs.uk

Received 12 May 2020

Accepted 19 June 2020

Published 6 July 2020

Production and Hosting by

Knowledge E

(c) Baha Eldin Hassan Juma et al. This article is distributed under the terms of the Creative Commons

Attribution License, which permits unrestricted use and redistribution provided that the original author and source are credited.

Editor-in-Chief:

Prof. Mohammad A. M. Ibnouf

\section{Abstract}

Background: Up to the point of writing this review, there is no scientific evidence of any effective medical therapy for coronavirus disease 2019 (COVID-19). In this review, we attempted to discuss the current summary of evidence of some medication, currently in trial for the treatment of COVID-19.

Material and Methods: We have done an electronic literature search using the following database: PubMed, Medline, Scopus and Google scholar. These databases were searched using the keywords COVID-19 and pharmacological therapy.

Results: At present, there are no well randomized controlled studies which can give evidence for most of the therapy used for COVID-19. Several medications are in trials for COVID-19, among them: 1/ chloroquine and hydroxychloroquine; 2/anti-virals oseltamivir, remdesivir, lopinavir/ritonavir and other protease inhibitors; 3/antibiotics macrolide (Azithromycin); 4/cytokine therapy interferon; 5/ humanized monoclonal antibody tocilizumab; 6/adjunct therapies vitamins C, D, and herbal medicine; 7/ COVID-19 convalescent plasma; 8/systemic steroids; 9/expected COVID-19 vaccine. We have also included some of the herbal medicines that are commonly and widely used in the Middle East, Asia as well in Sudan, (black seeds, honey and Acacia Nilotica). It is worth mentioning that these herbal medicines have shown benefits in treating other diseases, but the evidence of their benefit in COVID-19 still needs to be established. Conclusion: Currently there is no pharmacological therapy for the COVID-19. More research and randomized clinical trials are needed to find effective therapy or vaccine against COVID-19.

Keywords: COVID-19, Pharmacotherapy, herbal medicine, Sudan

\section{Introduction}

Since the declaration of COVID-19 as a pandemic in January 2020, the number of cases of infection and mortality continued to rise steadily, as have mortality rates [1-4]. The search for a treatment or vaccine is the main challenge for all scientists across the globe who work in this field. In this short review, we attempted to discuss some of the pharmacological therapies used or have potential benefit in COVID-19. 


\section{Material and Methods}

We have performed an electronic literature search using the following database: pub Med, Medline, Scopus and Google scholar. These databases were searched using the keywords COVID-19 and pharmacological therapy. The authors searched also using a combination of the following terms [(COVID-19) AND (therapy) AND (treatment)] OR the name of different medication with COVID19]. The search based on studies published in the English language without restriction for the publication date. However, most of the published materials were found to be published in 2020 .

\section{Results and Discussion}

\subsection{Chloroquine and hydroxychloroquine}

Chloroquine and hydroxychloroquine were shown to inhibit the replication of COVID-19 cells in vitro through increasing $\mathrm{pH}$ of lysosomes $[1,2]$ and other intracellular acidic organelles and preventing fusion of the virus to the host cell [4-7]. Also, chloroquine and hydroxychloroquine have an immunomodulatory effect that theoretically could contribute to an anti-inflammatory response in patients with viral infections. These agents were synthesized for the treatment of malaria and have been used for the treatment of other illnesses such as systemic lupus erythematosus and other rheumatic conditions [3]. They are generally well tolerated with commonly reported adverse effects like nausea, vomiting, itching and headache. Other serious adverse effects include QTc prolongation, hematologic toxicities, and hypoglycemia. These side effects are uncommon but require appropriate monitoring and patient selection [4]. Hydroxychloroquine and chloroquine can have significant drug interactions, especially with drugs with potential for QTc prolongation. Due to uncertainty in benefits and harms, infectious diseases society of America (IDSA) guidelines on the treatment and management of patients with COVID-19 recommends the use of hydroxychloroquine in the context of the clinical trial $[5,8]$. The guideline on the management of critically ill adults with COVID19 by the Surviving Sepsis Campaign (SSC) and the National Institute of Health (NIH) did not make a recommendation for or against its use, however, $\mathrm{NIH}$ recommended against the use of high dose hydroxychloroquine $[6,11]$.

\subsection{Azithromycin}

Azithromycin ( $\mathrm{C} 38 \mathrm{H} 72 \mathrm{~N} 2 \mathrm{O} 12)$ is a macrolide antibiotic that acts by inhibiting protein synthesis through binding to $50 \mathrm{~S}$ ribosomal subunit [9]. Macrolides are some of the most commonly prescribed antibiotics. They are used for a wide range of acute and chronic infections. Adverse events profile includes gastrointestinal symptoms, taste disturbance and hearing loss [10]. Azithromycin has been studied for the treatment of COVID-19 in combination with hydroxychloroquine. Although azithromycin itself is not usually associated with QTc prolongation, its use with hydroxychloroquine may increase the risk of torsades de pointes. Due to safety concerns and limited poor-quality evidence, 
Infectious diseases society of America (IDSA) and National Institutes of Health (NIH) recommend the use of hydroxychloroquine and azithromycin combination to be limited to clinical trials $[5,11]$

\subsubsection{Remdesivir}

Remdesivir (C27H35N6O8P) is an investigational broad-spectrum antiviral [5]. It causes premature termination of RNA transcription after conversion to an adenosine analogue. Although remdesivir is considered the most promising drug, IDSA, and SSC did not make recommendations regarding its use due to insufficient evidence. More recently, $\mathrm{NIH}$ recommended the use of remdesivir for patients hospitalized for severe COVID-19. It also recommended that its use for mild to moderate disease be limited to the setting of clinical trials [11]. It can cause gastrointestinal side effects, elevated liver enzymes and elevated prothrombin time $[5,6,12]$. First randomized, double-blind, placebo-controlled, multicenter trial of use remdesivir in adults with severe COVID-19 published in lancet last April 2020 included 237 patients were enrolled (158 to remdesivir and 79 to placebo). This study concluded that remdesivir use was not associated with a difference in time to clinical improvement $(95 \% \mathrm{Cl} 0.87-1.75)$ which is not statistically significant, however, patients receiving remdesivir had fast clinical improvement with symptom duration of 10 days or less [12].

\subsubsection{Oseltamivir}

Oseltamivir $(\mathrm{C} 16 \mathrm{H} 28 \mathrm{~N} 2 \mathrm{O} 4)$ is an antiviral drug used for treatment and prophylaxis of influenza $A$ and $B$. It exerts its action by inhibiting neuraminidases enzyme and preventing the release of the virus from the host cell [11]. Neuraminidases is not known to be found in SARS-CoV-2, thereby the mechanism is unclear. There the use of oseltamivir was already reported during the COVID-19 epidemic in China, either with or without antibiotics and corticosteroids [14], however, some trials studying oseltamivir as a part of a combination with chloroquine and favipiravir are underway [15].

\subsubsection{Lopinavir/ritonavir and other protease inhibitors}

Lopinavir (C37H48N4O5) is an antiretroviral drug used in combination with the pharmacokinetic enhancer ritonavir for the treatment of human immunodeficiency virus (HIV) [10]. Lopinavir inhibits 3-chymotrypsin-like protease of SARS-CoV-2 in vitro. Gastrointestinal adverse effects are commonly observed, in addition to possible QTc prolongation and elevated transaminases [11]. The Surviving Sepsis Campaign (SSC) guideline suggests against the use of lopinavir/ritonavir for treatment of COVID-19 in critically ill adults, while IDSA and NIH recommend limiting to clinical trials [5, 6, 13]. These recommendations are derived from the results of a small randomized controlled trial which failed to show the benefit of this intervention [13]. NIH also recommends limiting the use of other protease inhibitors to clinical trials, however SSC makes no recommendation on their use due to insufficient evidence $[6,10]$. Several trials involve lopinavir-ritonavir treatment 
in comparison with the use of other drugs for COVID-19 are going on, however the combination of lopinavir-ritonavir was associated with clinical improvement comparing with standard care procedures [13].

\subsection{Interferons}

Used for their antiviral activity, interferons are a group of cytokines that are being considered as a potential therapy for COVID-19. Many interferons have in vitro effect against SARS-CoV and MERS-CoV. They are usually used for the treatment of viral hepatitis and some types of malignancies. For the treatment of COVID-19, they are used in combination with ribavirin or lopinavir/ritonavir. Flu-like symptoms, hematologic toxicity and depression are amongst the most common adverse effects of interferons. The NIH recommends limiting the use of interferons to clinical trials while Surviving Sepsis Campaign was not able to issue a recommendation due to insufficient evidence $[6,10]$. During the writing of this review, in Hong kong, a multicenter, prospective, openlabel, randomized, phase 2 trial was conducted using Triple combination of interferon beta-1b, lopinavir-ritonavir, and ribavirin in the treatment of adult COVID 19 patients. More clinical trials are needed to evaluate the efficacy and safety of recombinant human interferon in treating patients with new coronavirus infection.

\subsubsection{Tocilizumab}

Tocilizumab is a humanized monoclonal antibody that inhibits interleukin-6. It is expected to suppress the possible high immune response in COVID-19 patients. It is used for the treatment of conditions like cytokine release syndrome and rheumatoid arthritis, but it is associated with an increased risk of infections [6]. NIH and SCC made no recommendation regarding the use of tocilizumab because of insufficient data, while IDSA recommends limiting its use to clinical trials settings [5, 6, 11]. Adequately powered randomized controlled trials are in need to determine the efficacy of tocilizumab with consideration of the toxicity of this medicine.

\subsubsection{COVID-19 Convalescent Plasma}

This is theoretically done by taking plasma which contains neutral antibodies from those who recovered from COVID-19 and transfused to patients with COVID-19. The rationale behind this therapy it could provide short-term passive immunity against COVID-19, decrease viral load and improves the outcome [17]. As reported at SARS pan epidemic 2003 use of convalescent plasma obtained from patients provide some benefits (shorter duration of hospitalization, decreased mortality). Moreover, those who received the plasma within less than 14 days from the start of symptoms have a better outcome [18]. Efficacy data are not available from controlled clinical studies to date. Multiple registered clinical trials initiated in the US and other countries to evaluate the use of COVID-19 convalescent plasma. IDSA and $\mathrm{NIH}$ did not make recommendations regarding the use of convalescent plasma outside of the clinical trial setting, however, SCC suggests 
against its routine use in critically ill adults. This recommendation is driven by previous studies for other viral infections like Ebola and influenza which showed no benefit. In addition to uncertainty regarding its preparation $[5,6,11]$.

\subsubsection{Systemic Corticosteroids}

The rationale of the use of systemic steroids to maintain a systemic anti-inflammatory that will minimize the symptoms of COVID-19 especially on those patients complicated with severe respiratory sequences (ARDS). However, WHO does not recommend the liberal use of systemic steroids unless patients are recruited in clinical studies or there is another medical indication [19]. Importantly, the use of steroid during the MERS epidemic was associated with increase in use of invasive ventilation and raised mortality rate at 90 days [20]. $\mathrm{NIH}$ (strong recommendation) and IDSA (conditional recommendation) do not support the routine use of corticosteroid. On the other hand, SCC (weak recommendation) and $\mathrm{NIH}$ (moderate recommendation) support the use of low dose corticosteroid in COVID-19 patients in refractory shock. For patients on mechanical ventilation without acute respiratory distress syndrome (ARDS), SCC (weak recommendation) and $\mathrm{NIH}$ (strong recommendation) do not recommend the use of corticosteroids, however, SCC suggests using corticosteroids for patients with ARDS $[5,6,11]$.

\subsubsection{Vitamins $C$ and $D$}

The use of vitamins $C$ and D was associated with many benefits in term of increasing the effectiveness of the immune system and increase wound healing with vitamin $C$. Interestingly, vitamin C infusion was associated with improvement in the prognosis of severe acute respiratory tract infections in COVID-19 patients and this could be attributed to the improvement of alveolar epithelization in severe respiratory distress syndrome patients $[21,22]$. Furthermore, vitamin $D$ has a role in mitigating the scope of acquired immunity and endothelial lining regeneration, hence this may minimize alveolar damage caused in ARDS. Vitamin D supplementation has a $12 \%$ overall protective effect against bacterial and viral acute respiratory tract infection [23]. Indeed, there is no harm from using these vitamins during the COVID-19.

\subsubsection{Vaccine}

There is currently no vaccine available to protect against COVID-19. Multiple registered clinical trials are ongoing worldwide in Europe and USA as well as Asia. One of the leading candidates is the mRNA-1273 vaccine which was developed by the National Institute of Allergy and Infectious Diseases (NIAID) scientists. This vaccine is currently in Phase I trial. The estimated completion time is June 2021 [24]. Once a safe and effective vaccine becomes available it will be vital that it is accessible to everyone who needs it (WHO reports). 
TABLE 1: Summary of current data on selected COVID-19 therapies.

\begin{tabular}{|c|c|c|c|}
\hline Drug & Preclinical data & $\begin{array}{l}\text { Safety } \\
\text { considerations }\end{array}$ & $\begin{array}{l}\text { Recommendations (outside the } \\
\text { context of clinical trials) }\end{array}$ \\
\hline Hydroxy-chloroquine & $\begin{array}{l}\text { inhibits the } \\
\text { replication of } \\
\text { COVID-19 cells in } \\
\text { vitro through } \\
\text { increasing pH of } \\
\text { endosomes. Also } \\
\text { has } \\
\text { immunomodulatory } \\
\text { effects }\end{array}$ & $\begin{array}{l}\text { QTc prolongation, } \\
\text { hematologic } \\
\text { toxicities, and } \\
\text { hypoglycemia }\end{array}$ & $\begin{array}{l}\text { NIH recommends against the } \\
\text { use of high dose } \\
\text { hydroxychloroquine }\end{array}$ \\
\hline Remdesivir & $\begin{array}{l}\text { Causes premature } \\
\text { termination of RNA } \\
\text { transcription after } \\
\text { conversion to an } \\
\text { adenosine } \\
\text { analogue }\end{array}$ & $\begin{array}{l}\text { gastrointestinal side } \\
\text { effects, elevated } \\
\text { liver enzymes and } \\
\text { elevated } \\
\text { prothrombin time }\end{array}$ & $\begin{array}{l}\text { Recommended by NIH for } \\
\text { patients hospitalized for severe } \\
\text { COVID-19 }\end{array}$ \\
\hline Lopinavir/ritonavir & $\begin{array}{l}\text { inhibits } \\
\text { 3-chymotrypsin-like } \\
\text { protease of } \\
\text { SARS-CoV-2 in vitro }\end{array}$ & $\begin{array}{l}\text { Gastrointestinal } \\
\text { adverse effects, } \\
\text { QTc prolongation } \\
\text { and elevated } \\
\text { transaminases }\end{array}$ & $\begin{array}{l}\text { SSC suggests against the use of } \\
\text { lopinavir/ritonavir for treatment of } \\
\text { COVID-19 in critically ill adults }\end{array}$ \\
\hline Interferon & $\begin{array}{l}\text { Many interferons } \\
\text { have in vitro effect } \\
\text { against SARS-CoV } \\
\text { and MERS-CoV }\end{array}$ & $\begin{array}{l}\text { Flu like symptoms, } \\
\text { hematologic toxicity } \\
\text { and depression }\end{array}$ & $\begin{array}{l}\mathrm{NIH} \text { recommends against the } \\
\text { use of interferons }\end{array}$ \\
\hline Tocilizumab & $\begin{array}{l}\text { suppress the } \\
\text { possible high } \\
\text { immune response } \\
\text { in COVID-19 }\end{array}$ & $\begin{array}{l}\text { increased risk of } \\
\text { infections }\end{array}$ & $\begin{array}{l}\text { IDSA recommends limiting its } \\
\text { use to clinical trials settings }\end{array}$ \\
\hline Convalescent plasma & $\begin{array}{l}\text { short-term passive } \\
\text { immunity against } \\
\text { COVID-19 }\end{array}$ & $\begin{array}{l}\text { Transfusion related } \\
\text { adverse events } \\
\text { including risk of } \\
\text { infection and } \\
\text { overload of blood } \\
\text { circulation }\end{array}$ & $\begin{array}{l}\text { SCC suggests against routine } \\
\text { use of convalescent plasma in } \\
\text { critically ill adults with COVID-19 }\end{array}$ \\
\hline Corticosteroids & $\begin{array}{l}\text { systemic } \\
\text { anti-inflammatory } \\
\text { that will minimize } \\
\text { the symptoms of } \\
\text { COVID-19 }\end{array}$ & $\begin{array}{l}\text { Possible increased } \\
\text { need for } \\
\text { mechanical } \\
\text { ventilation, } \\
\text { increased risk of } \\
\text { mortality }\end{array}$ & $\begin{array}{l}\text { 1. NIH (strong recommendation) } \\
\text { and IDSA (conditional } \\
\text { recommendation) do not support } \\
\text { routine use of corticosteroid. } \\
2 \text {. SCC (weak recommendation) } \\
\text { and NIH (moderate } \\
\text { recommendation) support the } \\
\text { use of low dose corticosteroid in } \\
\text { COVID-19 patients in refractory } \\
\text { shock. } \\
\text { 3. For patients on mechanical } \\
\text { ventilation without acute } \\
\text { respiratory distress syndrome } \\
\text { (ARDS), SCC (weak } \\
\text { recommendation) and NIH } \\
\text { (strong recommendation) do not } \\
\text { recommend the use of } \\
\text { corticosteroids. } \\
4 \text {. For mechanically ventilated } \\
\text { patients with ARDS, SCC } \\
\text { suggests using corticosteroid }\end{array}$ \\
\hline
\end{tabular}




\subsubsection{Traditional and herbal medicine}

Many reports and news from cultural and religious background reported some herbal traditional medicine have been used with no scientific background or pharmacological evidence. Reports from china that Chinese herbal formula might be associated with blocking of the proliferation and replication of the virus particles, therefore, can minimize viral load sequences.

Natural honey was also widely used during COVID-19 in these countries, either alone or in combination with Nigellla sativa. Certain herbs, if misused, could boost the immune system even more and lead to "a cytokine storm," or a fatal overactive immune response, according to Gersh [25]. Hence, efforts from health authorities to restrict use are highly appreciated as these are not well scientifically studied. Despite the popularity of herbal medicine in Sudan, no clinical studies or randomized clinical trials have yet assessed the use of these herbal medicines.

\section{Conclusion}

The world is in a race to find effective treatment and vaccine against COVID-19. This will continue to be challenging disease, as we have not yet developed a full understanding of the pathogenesis of COVID-19. Summary of possible potential therapy of COVID-19 was provided in table 1. Drug discovery and clinical trials will need time, and many peoples may suffer or die as a result of this long wait. The discovery of vaccine or pharmacological therapy against COVID-19 will be the main success in getting out of the lockdown of COVID-19.

\section{References}

[1] Browning D.J. (2014) Pharmacology of Chloroquine and Hydroxychloroquine. In: Hydroxychloroquine and Chloroquine Retinopathy. Springer, New York, NY.

[2] Keyaerts E., Vijgen L., Maes P., et al. (2004). In vitro inhibition of severe acute respiratory syndrome coronavirus by chloroquine. Biochem Biophys Res Commun, vol. 323, pp. 264-8. (DOI 10.1016/j. bbrc.2004.08.085)

[3] Scuccimarri R., Sutton E. and Fitzcharles M. (2020). Hydroxychloroquine: a potential ethical dilemma for rheumatologists during the COVID-19 pandemic. 2020 Jun 1;47(6):783-786

[4] Juurlink DN. Safety considerations with chloroquine, hydroxychloroquine and azithromycin in the management of SARS-CoV-2 infection. CMAJ. 2020;192(17):E450-E453. doi:10.1503/cmaj.200528

[5] Bhimraj A., Morgan R. and Shumaker A. (2020, April). Infectious Diseases Society of America Guidelines on the Treatment and Management of Patients with COVID-19. Idsociety.org. Available from: https: //www.idsociety.org/practice-guideline/covid-19-guideline-treatment-and-management/

[6] Alhazzani W., Møller M.H., Arabi Y.M. et al. (2020). Surviving Sepsis Campaign: guidelines on the management of critically ill adults with Coronavirus Disease 2019 (COVID-19). Intensive Care Med Surviving Sepsis Campaign-Vol - 46-DO - 10.1007/s00134-020-06022-5JO - Intensive Care Medicine

[7] Liu J., Cao R., Xu M., et al. (2020). Hydroxychloroquine, a less toxic derivative of chloroquine, is effective in inhibiting SARS-CoV-2 infection in vitro. Cell Discov., vol. 6, pp.1-4. (DOI 10.1038/s41421-020- 0156-0)

[8] Geleris J., Sun Y. and Platt J, (2020). Observational Study of Hydroxychloroquine in Hospitalized Patients with Covid-19 .I N Engl J Med- 2020 Jun 18;382(25):2411-2418.

[9] Valentin F. TY - BOOK-AU - Valentin, Frank-PY - 2020/03/28SP - T1 - Azithromycin and COVID-19 History and Review-DO -10.13140/RG.2.2.33299.63524 
[10] Hansen M.P., et al. (2019). Adverse events in people taking macrolide antibiotics versus placebo for any indication. Cochrane Database of Systematic Reviews 2019, Issue 1. Art. No.: CD011825. DOI: 10.1002/14651858.CD011825.pub2.

[11] COVID-19 Treatment Guidelines Panel. Coronavirus Disease 2019 (COVID-19) Treatment Guidelines. National Institutes of Health. Available at https://www.covid19treatmentguidelines.nih.gov/. assessed $25 / 5 / 2020$

[12] Wang Y, Zhang D, Du G, et al. Remdesivir in adults with severe COVID-19: a randomised, doubleblind, placebo-controlled, multicentre trial [published correction appears in Lancet. 2020 May 30;395(10238):1694]. Lancet. 2020;395(10236):1569-1578. doi:10.1016/S0140-6736(20)31022-9

[13] Cao B, Wang Y, Wen D, et al. A Trial of Lopinavir-Ritonavir in Adults Hospitalized with Severe Covid-19. N Engl J Med. 2020;382(19):1787-1799. doi:10.1056/NEJMoa2001282

[14] Wang D., et al. (2020). Clinical Characteristics of 138 Hospitalized Patients With 2019 Novel CoronavirusInfected Pneumonia in Wuhan, China. JAMA. 2020 Feb 7;323(11): 1061-1069.doi: 10.1001/jama.2020.1585

[15] Bethesda (MD), National Library of Medicine (US) (2020 Mar 12). Various combination of Protease Inhibitors, Oseltamivir, Favipiravir, and Chloroquin for Treatment of COVID-19: A Randomized Control Trial (THDMS-COVID19). https://clinicaltrials.gov/ct2/show/NCT04303299

[16] Fan-Ngai H.I., Kwok-Cheung L. andYuk-Keung T.E. (2020). Triple combination of interferon beta-1b, lopinavir-ritonavir, and ribavirin in the treatment of patients admitted to hospital with COVID-19: Lancet. 2020 May 30;395(10238):1695-1704. doi: 10.1016/S0140-6736(20)31042-4. Epub 2020 May 10

[17] Shen C, Wang Z, Zhao F, et al. Treatment of 5 Critically III Patients With COVID-19 With Convalescent Plasma. JAMA. 2020;323(16):1582-1589. doi:10.1001/jama.2020.4783

[18] Kai D., - et al. (2020). Effectiveness of convalescent plasma therapy in severe COVID-19 patients. In Proceedings of the National Academy of Sciences vol. 117, issue 17, pp.94909496. DOI: 10.1073/pnas.2004168117

[19] World Health Organization. (2020). Clinical management of severe acute respiratory infection (SARI) when COVID-19 disease is suspected: interim guidance, 13 March 2020. World Health Organization. https://apps.who.int/iris/handle/10665/331446. License: CC BY-NC-SA 3.0

[20] Arabi M.Y., Al-Omari A.A. and Mandourah M.Y. (2017). Critically ill patients with the Middle East respiratory syndrome: a multicenter retrospective cohort study. Crit Care Med., vol. 45, pp. 1683-1695.

[21] Peng, Z.Y. - (2019). Vitamin C Infusion for the Treatment of Severe 2019-nCoV Infected Pneumonia. clinicaltrials.gov > ct2 > show > NCT04264533-US national library of medicine- https://clinicaltrials.gov/ ct $2 /$ hom

[22] : Rodrigues da Silva M, Schapochnik A, Peres Leal M, Esteves J, Bichels Hebeda C, Sandri S, et al. (2018) Beneficial effects of ascorbic acid to treat lung fibrosis induced by paraquat. PLoS /ONE 13(11): e0205535. https://doi.org/10.1371/journal.pone.0205535

[23] Martineau Adrian R, Jolliffe David A, Hooper Richard L, Greenberg Lauren, Aloia John F, Bergman Peter et al. Vitamin D supplementation to prevent acute respiratory tract infections: systematic review and meta-analysis of individual participant data BMJ 2017; 356: i6583

[24] National Institute of Allergy and Infectious Diseases (NIAID),author. NIH clinical trial of investigational vaccine for COVID-19 begins Study enrolling Seattle-based healthy adult volunteers. https://corona. kpwashingtonresearch.org/

[25] Ries, J. (2020). Herbal Remedies and COVID-19: What to Know. Cassell- https://www.healthline.com/ health-news/herbal-remedies-covid-19-what-to-know 